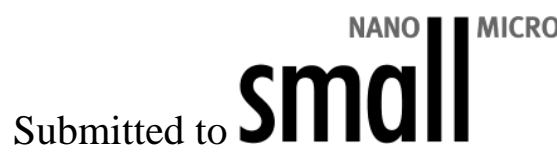

DOI: 10.1002/smll.((please add manuscript number))

\title{
Vapor-Phase Hydrothermal Growth of Novel Segmentally Configured Nanotubular Crystal Structure**
}

By Porun Liu, Haimin Zhang, Hongwei Liu, Yun Wang, Taicheng An, Weiping Cai, Huagui Yang, Xiangdong Yao, Guangshan Zhu, Robyn Webb and Huijun Zhao*

[*] Prof. H. J. Zhao, Dr. P. R. Liu, Dr. H. M. Zhang, Dr. H. W. Liu, Dr. Y. Wang, Prof. H. G. Yang

Centre for Clean Environment and Energy

Griffith School of Environment

Griffith University

Queensland 4222 (Australia)

E-mail: h.zhao@griffith.edu.au

Prof. T. C. An

State Key Laboratory of Organic Geochemistry

Guangdong Key Laboratory of Environmental Resources Utilization and Protection

Guangzhou Institute of Geochemistry, Chinese Academy of Sciences

Guangzhou 510640 (P. R. China)

Prof. W. P. Cai, Prof. H. J. Zhao

Key Laboratory of Materials Physics

Hefei Key Laboratory of Nanomaterials and Nanotechnology

Institutes of Solid Sate Physics, Chinese Academy of Sciences

Hefei 230031 (P. R. China)

Prof. H. G. Yang

Key Laboratory for Ultrafine Materials of Ministry of Education

School of Materials Science and Engineering

East China University of Science and Technology

Shanghai 200237 (P. R. China)

A. Prof. X. D. Yao, Prof. G. S. Zhu

QLD Micro- and Nanotechnology Centre

Griffith University,

Queensland 4111 (Australia)

Ms. R. Webb

Centre for Microscopy and Microanalysis

The University of Queensland, St Lucia

Queensland 4072 (Australia)

Authors acknowledged the financial support by Australian Research Council and technical assistance by the Australian Microscopy \& Microanalysis Research Facility (AMMRF) at the Centre for Microscopy and Microanalysis (CMM), the University of Queensland.

Supporting Information is available on the WWW under http://www.small-journal.com or from the author.

Keywords: Nanotube structure, Vapor-phase, Hydrothermal synthesis, Controllable growth, Growth mechanism 


\section{subinates small}

Unique structural, geometrical and physiochemical properties of one-dimensional (1D) multilayer nanotubular materials make them a class of promising functional nanomaterials for a wide range of applications. ${ }^{[1]}$ Diversified multilayer nanotubes such as carbon, metal sulphides and metal oxides nanotubes have been synthesized in laboratory. ${ }^{[1 \mathrm{~b}, 1 \mathrm{f}, 2]}$ With regard to crystal structure, the vast majority of synthesized the multilayer nanotubes to date are either in seamless co-axial cylindrical ${ }^{[1 \mathrm{a}, 1 \mathrm{e}, 3]}$ or scroll-like arrangement. ${ }^{[1 \mathrm{c}, 1 \mathrm{~d}, 4]}$ However, only few nanotubes' crystal structures have been decisively confirmed with sufficient experimental evidence support. ${ }^{[5]}$ This is especially true for $\mathrm{TiO}_{2}$ nanotubes, ${ }^{[2 \mathrm{i}, 21,4,6]}$ of which only one report confirms the seamless coaxial cylindrical structure while scroll-like crystal structures have not yet been confirmed. ${ }^{[3]}$ As far as the formation mechanism is concerned, for hydrothermally synthesized metal oxide nanotubes, $\mathrm{TiO}_{2}$ nanotubes in particular, although extensive studies have been reported, the precise mechanistic pathways are still unclear and often controversial due to the lack of direct experimental evidence support, especially the precise crystal structural information. ${ }^{[3]}$ From synthesis methodological points of view, the liquid-phase hydrothermal (LPH) methods have been widely used to obtain large quantity metal oxide nanotubes. ${ }^{[2 \mathrm{i}, 21,4,6]}$ However, for fabrication of $\mathrm{TiO}_{2}$ nanotubes, $\mathrm{LPH}$ methods is only capable of producing nanotubes with a narrow diameter range $(8-12 \mathrm{~nm})$ while the controllable growth of nanotubes with wider range of dimensions, shapes and crystal structures has not been succeeded. ${ }^{[2 i, 21,4,6]}$

We recently reported new vapor-phase hydrothermal (VPH) methods using $\mathrm{NH}_{3}$ and $\mathrm{HF}$ vapor phases to fabricate $\mathrm{TiO}_{2}$ based nanomaterials with controllable geometry, dimension and crystal facets. ${ }^{[3,7]}$ With $\mathrm{NH}_{3}$ vapor phase, we successfully fabricated large quantity of titanate nanotubes that differ significantly to those obtained from conventional LPH conditions in terms of tubular geometry, dimension and crystal structure. ${ }^{[3]}$ For the first time, a nanosheet rolled-up mechanism to form larger diameter titanate nanotubes with high 


\section{sanizususmall}

crystallinity and co-axial cylindrical crystallographic structure is categorically confirmed. More importantly, the studies revealed that the unique reaction environment created under VPH conditions is responsible for the differences of the resultant nanostructures and formation mechanisms. ${ }^{[3,7]}$ In strong contrast to a LPH method, all VPH reactions occur within a thin-liquid layer reaction zone formed on the surface of the substrate. The dissolution products can rapidly reach a supersaturating status in the thin-liquid layer reaction zone (with small volume) to facilitate the structure formation. Also, the mass transport limitation within the thin liquid-layer reaction zone makes the dissolution/precipitation (structure formation) highly localized. Herein, we demonstrate for the first time of a new nanotubular crystal structure via an oriented crystal growth mechanism using a facile VPH method. Strongly differed from any given nanotube structural model, a multi-tunneled layered nanotubular structure with droplet shaped polygonal periphery consist of single-crystal-like segments has been categorically confirmed. Systematic investigation shows the distinctive nanotube formation can be attributed to an epitaxial crystal growth oriented by the titanate precursor. The as-prepared nanotubes possess superior ion exchange properties that make them useful candidates for diversified applications.

The $\mathrm{NaOH}$ coated porous titanate-grown Ti foil precursor (Figure S1) was employed for the nanotube growth under $\mathrm{NH}_{3}$-saturated vapor conditions (Figure S2). Figures 1a, $\mathrm{d}$ and g show the scanning electron microscopy (SEM) images of the directly grown titanate nanotubes via LPH approaches in $10 \mathrm{~mol} \mathrm{~L}^{-1} \mathrm{NaOH}$ solution and VPH approaches with different amounts of pre-coated $\mathrm{NaOH}$ (see experimental details). Hereafter, these samples are denoted as $\mathrm{LPH}$, VPH I and VPH II for simplicity. The nanotubes obtained from VPH methods exhibit remarkably larger external widths and more layers of wall structure (i.e., $37.4 \mathrm{~nm}$ with 23 layers for VPH I and $82.5 \mathrm{~nm}$ with 45 layers for VPH II) than that obtained from LPH method (9.0 nm with 3 layers) (Figures $1 \mathrm{~b}$, e and $\mathrm{h}$ ). The inner widths of the all nanotube tunnels are 


\section{sanizusus small}

$\sim 5 \mathrm{~nm}$. The interlayer distance measurements of over 40 nanotubes by transmission electron microscopy (TEM) reveal an average values of 7.7 and $7.5 \AA$ for VPH I and VPH II nanotubes. The X-ray diffraction (XRD) data show identical reflection peaks for all samples (Figure S3), that can be assigned to a lepidocrocite-type titanate, $\mathrm{H}_{0.7-\mathrm{x}-}$ ${ }_{\mathrm{y}} \mathrm{Na}_{\mathrm{x}}\left(\mathrm{NH}_{4}\right)_{\mathrm{y}} \mathrm{Ti}_{1.825} \square_{0.175} \mathrm{O}_{4} \cdot \mathrm{H}_{2} \mathrm{O}$ (where, $\square=$ vacancy), ${ }^{[3]}$ a cation exchanged product of bodycentered orthorhombic $\mathrm{H}_{0.7} \mathrm{Ti}_{1.825} \square_{0.175} \mathrm{O}_{4} \cdot \mathrm{H}_{2} \mathrm{O}{ }^{[8]}$ The selected area electron diffraction (SAED) patterns of the nanotube walls recorded with incident beam perpendicular to the tube axes are shown in Figures 1c, f and i. They can be indexed as the $(h k 0)$ reflections with [001] zone axis. Compared with the LPH sample, higher indexed reflection spots are well resolved in the VPH samples (Figures 1f and i), indicating high crystallinity. It is noted that the (020) plane is depressed due to the dehydration of interlayer water molecules (about 30\%) during the high vacuum in TEM observation. ${ }^{[8]}$ However, no such plane spacing reduction is detected in the ambient pressure XRD measurement (Figure S3). The Raman spectra of the nanotubes with different thickness are consistent with the XRD data (Figure S4). It is revealed that characteristic phonon modes at 190, 274, 385, 446, 670, 704, 827 and $914 \mathrm{~cm}^{-1}$ are to the vibrations of lepidocrocite-type titanate. ${ }^{[6 \mathrm{~d}, 8 \mathrm{~b}, 9]}$ The bands 670 and $704 \mathrm{~cm}^{-1}$ are related to the vibration modes of nanotube surfaces ${ }^{[9 b]}$ From the XRD and Raman data, it is conclusive that the titanate nanotubes prepared in LPH and VPH methods share analogous crystal structures.

In the TEM observation, nanotubes with multiple inner tunnels were occasionally detected, particularly for VPH II samples (Figure S5). This is in strong conflict with the common coaxial circular cylindrical ${ }^{[1 \mathrm{la}, 1 \mathrm{e}, 3]}$ or scroll model, ${ }^{[1 \mathrm{cc}, 1 \mathrm{~d}, 4]}$ which presumably possess only a single tunnel. We therefore studied the nanotubes' structure by directly examining the tubular cross-section structure. Figure 2a shows a typical cross-sectional TEM image of a VPH II nanotube viewed along the tube axis. In contrast to a perfect tubular geometry, a dropletshaped cross-section image was observed with several internal tunnels. More interestingly, the 


\section{sanizusus small}

nanotube wall was found to be configured with hierarchical "core-shell" alike aggregative layers that each consists of a number of individual layers with the spacing of $\sim 7.5 \AA$ (Figure 2a). The aggregative "core" layer structures are found to be irregular in terms of size, shape and position (Figure S6). The "external" surface of core layers is partially attached to the "internal" intrados of the "shell" with the rest being exposed to the inner tunnels. This finding implies that the tubular tunnel shown in Figures 1e, $\mathrm{h}$ represent the width of the innermost tunnel rather than sub-tunnels occasionally formed between adjacent aggregative layers. Moreover, in contrast to a perfect seamless circular geometry, external "shell" exhibits a polygonal shaped outer profile with each polygonal section being formed by a segment of single-crystal-like block, ${ }^{[1 e, 10]}$ as illustrated in the schematically reconstructed tubular crosssection images (Figure 2b). The high resolution TEM (HRTEM) image was hence obtained to reveal the detailed crystallographic arrangement (Figure 2c). Although the size of segment may vary, the outline angle $\left(18^{\circ}\right)$ between the neighbor segments obeys a specific crystallographic arrangement. An $81^{\circ}$ discrepancy angle between the neighbor segment boundary and the (020) plane representing the angle between (020) and (011) planes of lepidocrocite-type titanate crystal determines an $18^{\circ}$ outline angle between the neighbour segments. These results imply that the single-crystal-like segments could be jointed to each other by sharing twinning (110) planes, of which crystallographic arrangement is shown in Figure 2d. Consistent with the TEM results, the SAED patterns of the nanotubes with the incident beam along the tube axis display (020) plane reflection dots with similar discrepancy angle of $18^{\circ}$ (Figure S6). Such a polygonal segment configured nanotubular structure represents a perfect crystal arrangement to reduce the interlayer tension and overall energy. ${ }^{[1]}$

Figure 2e shows the HRTEM image of another unique structural characteristic - a seaming ridge on the periphery observed for each individual nanotube. Viewed from the tube axis, the layers tend to join each other at these locations to form an arrow-shaped extrusion, which can 


\section{sunums small}

be more clearly demonstrated by Figure $2 \mathrm{f}$. A detailed crystallographic analysis of the extrusion shows that the angle between the seaming plane and layer (020) plane is $36^{\circ}$, which is consistent with the angle between (071) and (020) planes, strongly indicating that the two segments in the seaming ridge may be seamed by sharing of the twinning (071) plane (Figure $2 b$, e, and f). To our best knowledge, this is the first time that a droplet shaped "core-shell" multilayered nanotube structure has been demonstrated. The cross-sectional TEM image of smaller size nanotubes from VPH I sample shows analogous polygonal segmental crystallographic arrangement with less shell layers (Figure S7).

The above results demonstrated that in terms of size, geometry and crystallographic arrangement, the nanotubes in present work differ remarkably from any previously reported $\mathrm{TiO}_{2}$-based nanotubes, ${ }^{[2 \mathrm{i}, 21,4,6]}$ suggesting the formation mechanism could also differ significantly from the known ones. Targeted experiments were therefore performed to understand the growth pathway and formation mechanism. The side-viewed SEM images show that all nanotubes were grown directly from the porous precursor (Figure S8). Also, the crossing-grown nanotubes can be observed (Figure S9). The TEM image of an "injured" nanotube due to the crossing-growth shows that the rest part of the nanotube remains unimpaired and the nanotube growth direction or size had not been affected by crossinggrowth (Figure S9). Obviously, such a crossing-growth phenomenon can not be explained by the nanosheet rolling-up growth mechanism. ${ }^{[3,12]}$ The SEM and cross-sectional TEM images of nanotubes at different growth stages are therefore obtained to illustrate the growth pathway (Figure 3). Under the VPH conditions, a thin aqueous alkaline layer (reaction zone) can be instantly formed on the substrate by the saturated ammonia vapor, leading to a rapid dissolution of titanium species to form titanate building blocks. The concentration of the produced building blocks rapidly saturates the thin layer reaction zone, leading to the precipitation of outshoot seeding structures onto the substrate as the arrow pointed in Figure 


\section{santisus small}

3a. It is evident that such outshoot-like seeding structures serve as the base for nanotube formation (Figure 3a, Figure S8). The TEM image shows that such infant nanotubes possess several curved titanate layers (Figure 3e), as schematically illustrated in Figure 3i. The crystallization is found to be initiated at the adjacent area on one side of the seeding outshoot arranged in a layer-by-layer fashion by the tiny titanate building blocks to form a curved hump-like infant nanotubular structure. According to the crystallographic arrangement shown in Figure 2, the crystal orientations of the titanate building blocks must match perfectly to the crystal orientations of the exposed crystal surfaces of the already formed tubular structure before they can be built onto the tubular structure. That is, the tubular structure formation process shown here is an epitaxial crystal growth process. At this stage, the rates of the orientated crystal growth along the axial $a$ direction (elongation), the radial $b$ direction (thickening) and the tangential $c$ direction (encirclement) are similar, as illustrated in Figure 3i. As the reaction progresses, the structural expansion to all directions via the layer-by-layer epitaxial orientated crystal growth can be observed, leading to a longer semi-cylindrical shaped infant nanotube (Figures $3 \mathrm{~b}, \mathrm{f}$, and $\mathrm{j}$ ). As the precipitation process proceeds, the building blocks continue adding to the exposed vertical section from the innermost to the outermost layer as indicated by the observed stair-like layer structure in Figure 3c. It is to note that polygonized periphery can be clearly observed at this stage of growth, but the encirclement of the tubular wall has not yet been completed, as shown by the TEM image (Figure $3 \mathrm{~g}$ ) and schematic diagram (Figure $3 \mathrm{k}$ ). This is followed by a critical seaming process to complete the tubular wall encirclement, leading to the formation of a seaming ridge (Figures $3 \mathrm{~d}, \mathrm{~h}$, and 1). Rather than directly fill the gap to complete the encirclement in a seamless cylinder, the sites tend to merge and extrude outwards to form an arrow-shaped seaming ridge along the tubular axis. This could be due to rigidity of the preformed singlecrystal-like nanotube wall segments and when the sizes of the titanate building blocks are 


\section{sanumusmall}

larger than the sizes of the last remaining gaps, the formation of an arrow-shaped seaming ridge to complete the encirclement is the most effective means to reduce the tension force and system energy. It should be mentioned that in order to satisfy the requirements for the epitaxial orientated crystal growth, the crystal orientations of the building blocks for seaming must on one end match the crystal orientations of the growing sties at the tubular structure and on another end match each other's crystal orientations to seam the nanotube wall. After the seaming process is completed, the crystal growths occur mainly on the axial $a$ direction, leading to a steady increase in the tubular length. Beyond this stage, the growths on radial $b$ direction are minimal. The proposed pathway implies that the width of the innermost tunnel (Figure 1) is defined by the size of the outshoot-like seeding structures.

The above experimental results have decisively confirmed an epitaxial orientated crystal growth process under the VPH conditions. This is very different to the reported oriented crystal growth mechanism ${ }^{[13]}$ under LPH conditions for which the authors proposed that the seeding nanoloops generated by rolling-up of thin nanosheets in the initial stage of LPH process served as the bases and the crystal growth was subsequently occurred along the axial direction to achieve the elongation.. Such discrepancy in formation mechanisms can be attributed to the differences in reaction environments between LPH and VPH methods. ${ }^{[3]}$ In fact, the differences in size, geometry and crystal structure of the resultant nanotubes can also be attributed to the dramatically different reaction environment created under LPH and VPH conditions. For the LPH reaction, for example, the dissolved titanium species need to undergo a bulk solution process to form the basic building blocks and structural formation could start only when the entire bulk solution has been saturated. In this process, the formed building blocks can be re-dissolved and/or reconstructed, and dislocated to anywhere within the bulk solution, which makes the dissolution/precipitation processes constantly under a "semiequilibrium" status, regardless of reaction conditions. This leads to the formation of small but 


\section{sanizusus small}

uniform sized building blocks hence the similar nanotube diameters under different LPH conditions. $^{[2,21,4,6]}$ Comparatively, the dissolution and precipitation processes under VPH conditions are more rapid, dynamic and localized due to the small volume of the thin layer reaction zone that greatly limits the mobility of the dissolved titanium species but allows rapid mass transport from the vapor phase. Under such conditions, localized supersaturation by the dissolved titanium species can be rapidly achieved, leading to the formation of larger sizes titanate building blocks that have little or no time to undergo re-dissolving and/or reconstruction processes before locally precipitated to produce thicker nanotubes. We have previously demonstrated that using pure titanium substrate under similar VPH conditions, the obtained nanotubes possess a seamless co-axial cylindrical crystal structure, ${ }^{[3]}$ differing remarkably from the observed segmentally configured nanotubes. With the pure titanium substrate, the nanotubes are formed by a distinctive nanosheet rolling-up mechanism, contrasting strongly to the determined epitaxial orientated crystal growth mechanism in this work. A major difference between the two cases is that a porous crystalline titanate precursor is employed to replace the pure titanium substrate, suggesting the precursor can be a decisive factor affecting the size, geometry and crystal structure of the resultant nanotubes, and the formation mechanism.

Unlike carbon nanotubes, ${ }^{[14]}$ whose diameters play decisive role for the nature of their band structure, the as-prepared titanate nanotubes in present study share similar optical and electronic properties. Figure S10 shows the nearly identical UV-Vis absorption spectra of the three titanate nanotube samples, indicates that the optical properties of the nanotubes are independent of their dimensions. The band gap energy for the as-prepared titanate nanotubes are estimated to be about $3.7 \mathrm{eV}$ by obtaining a zero intercept of the plot of $F(R)^{2}$ (KubelkaMunk functions) against photon energy. 


\section{sanizususmall}

Titanate nanotubes have demonstrated practical potential as photocatalyst, photovoltaic materials, of which performance depends largely on their optical and electronic properties. Also, their well aligned, open-up, negative charged layered structures allow intercalation and exchange of free ions within the host layer cavity, which make them versatile candidates as support for distribution of various noble and transitional metal catalysts or dopants in atomic scale. ${ }^{[15]}$ High exchange capacity and short loading time are the two principal criteria for effective ion exchange process. In present study, the ion exchange properties of the asprepared titanate nanotubes are investigated by the kinetics of $\mathrm{H}^{+}$exchange with $\mathrm{Na}^{+}$upon addition of $\mathrm{NaOH}$ solution into protonated nanotubes suspension. ${ }^{[15 \mathrm{c}]}$ Within the layer structure and on the surface of the titanate nanotubes located large amount of ion exchangeable cations or protons. ${ }^{[16]}$ The ion exchange process can be illustrated as:

$$
x N a^{+}+N a_{y} H_{2-y} \mathrm{Ti}_{n} \mathrm{O}_{2 n+1} \Leftrightarrow N a_{x+y} \mathrm{H}_{2-x-y} \mathrm{Ti}_{n} \mathrm{O}_{2 n+1}+x \mathrm{H}^{+}
$$

In the protonated nanotube samples, small amount of residual $\mathrm{Na}$ ions are present. They are strongly incorporated with the nanotube and crucial for the stabilizing the tubular structures. ${ }^{[16 \mathrm{~b}]}$ Ion exchange in concentrated acid (e.g., $1 \mathrm{M} \mathrm{HNO}_{3}$ ) can remove these portion of $\mathrm{Na}$ ions leading to the collapse of the nanotubular structure. ${ }^{[16 \mathrm{~b}]}$ In our experiment, the nanotubular structures of both protonated LPH and VPH samples were preserved due to the mildly concentrated acid employed. After exchange with the $\mathrm{Na}^{+}$, the intercalated $\mathrm{H}^{+}$in the protonated titanate nanotubes will be extracted from the host layer and dissociate into the suspension, which will lead to a $\mathrm{pH}$ drop. The inset of Figure 4a shows the $\mathrm{pH}$ variation of the suspension mixture. After the addition of $\mathrm{NaOH}$ solution, the $\mathrm{pH}$ value of the titanate nanotube samples will dramatically reach about $11-12$ and start to decay as the $\mathrm{H}^{+}$ions accumulate and eventually reach a steady state where the equation (1) reaches the equilibrium. The slow $\mathrm{pH}$ decay of blank sample without titanate nanotube is due to the trace consumption of $\mathrm{NaOH}$ by the uptake of atmospheric $\mathrm{CO}_{2}$. As the plots of $\left[\mathrm{H}^{+}\right]$growth against 


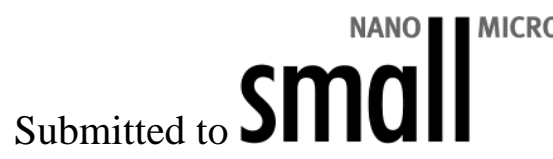

time collapsed shown in Figure 4, it is evident that proton concentrations of both VPH samples increased steadily after the addition of $\mathrm{NaOH}$ solution and levelled off in 25 and 35 min for VPH II and VPH I titanate nanotubes. For LPH sample, however, no significant increase of $\left[\mathrm{H}^{+}\right]$is observed in the initiative 20 minutes. The figure climbed up in a slow rate within 20 - $40 \mathrm{~min}$ before the increase trend was slowed down at $40 \mathrm{~min}$. More importantly, in terms of exchange capacity, the resultant $\left[\mathrm{H}^{+}\right]$values after 60 min ion-exchange for VPH samples are 9.6, $8.7 \times 10^{-8} \mathrm{~mol} \mathrm{~L}^{-1}$, about three folds of their LPH counterparts $\left(2.9 \times 10^{-8} \mathrm{~mol}\right.$ $\mathrm{L}^{-1}$ ). These results strongly indicate that the VPH titanate nanotubes possess dominant numbers of ion exchange sites that are able to accommodate the cations or protons, and provide easy access for other ions.

The size dependence of ion exchange behaviours has been investigated (Figure $4 \mathrm{~b}$ ). Smaller $\left(\mathrm{Li}^{+}, 90 \mathrm{pm}\right)$ and larger $\left(\mathrm{Ba}^{2+}, 149 \mathrm{pm}\right.$, close to radioactive $\left.{ }^{226} \mathrm{Ra}^{2+}\right)$ cations with distinctively different ionic diameters were selected. The results (Figure S11 and Figure 4b) suggest that ion exchange rate and capacities of VPH nanotubes are largely influenced by the size of exchange guest cations. The smaller size cations $\left(\mathrm{Ba}^{2+}>\mathrm{Na}^{+}>\mathrm{Li}^{+}\right)$will result in faster exchange rate and larger capacities. In contrast, proton exchange within LPH nanotubes by different cations exhibits comparable rates and capacities (Figure S11 and Figure 4b). ${ }^{[15 c]}$ This result alludes to the fact that the exchangeable protons for LPH samples are mainly located on the surface of the nanotubes, ${ }^{[16]}$ which can be replaced by the metal cations without intercalating into the layer structures. On the other hand, the as-prepared VPH nanotubes possess segmentally configured nanotubular structure with improved crystallinity and minimized lattice strain (as shown in Figure 2). ${ }^{[11]}$ It allows a well established, less-defect and stabilized lamellar matrix for the ion exchange processes (especially for smaller metal ions). Moreover, as the transport of the ions in the nanotubes can occur effectively along the tubular axis, ${ }^{[15 c]}$ the enhanced cross-sectional areas (effective exchange area) of the VPH samples 


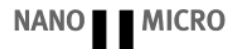 \\ suminitat $\operatorname{small}$}

may provide thorough diffusion pathways to allow efficient ion transport in and out spontaneously, leading to optimal ion exchange rate and capacity of VPH nanotube samples.

We have demonstrated for the first time, a VPH method to directly grow a new form of nanotubular crystal structure onto a porous crystalline titanate precursor substrate via a distinctive epitaxial orientated crystal growth mechanism. The confirmed multi-tunneled nanotubular structure, having droplet shaped polygonal periphery and segmental crystal configuration has never been reported. The formation mechanism and crystal configuration demonstrated in this work would have wide implications for applications of VPH method to other metal oxide systems. The novel nanotubular structure with superior ion exchange properties demonstrated herein can be adopted as catalyst supports, absorbent materials for hazard/radioactive metal, component materials for lithium ion batteries, supercapacitor and hydrogen storage.

\section{Experimental Section}

Synthesis: The porous titanate precursor was firstly fabricated onto a titanium metal plate. Typically, a titanium plate was placed at the bottom of a Teflon lining with $\mathrm{NaOH}$ aqueous solution $\left(10 \mathrm{~mol} \mathrm{~L}^{-1}\right)$. The lining was sealed, assembled in a stainless autoclave and kept at $150^{\circ} \mathrm{C}$ for $1 \mathrm{~h}$ in an oven. After the reaction, the titanium plate was removed from the solution, rinsed in highly purified water for 3 times $(50 \mathrm{~mL}$ each time), soaked in water for $24 \mathrm{~h}$ and finally dried at room temperature under vacuum over night. The obtained porous titanate precursor was used as the substrate to grow titanate nanotubes. $\mathrm{A} \mathrm{NaOH}$ solid layer was coated onto the surface of precursor by vertical withdrawing the titanium plate from freshly made $\mathrm{NaOH} / \mathrm{alcohol}$ solutions and dried at $60{ }^{\circ} \mathrm{C}$ in a vacuum oven for $30 \mathrm{~min}$. The external widths of the nanotubes were readily controlled by the amount of $\mathrm{NaOH}$ coating. To obtain VPH I and VPH II sample, $\mathrm{NaOH} /{\text { methanol solution }\left(4 \mathrm{~mol} \mathrm{~L}^{-1}\right) \text { and } \mathrm{NaOH} / \mathrm{ethanol}(2 \mathrm{~mol} \mathrm{~L}}^{-}$

$\left.{ }^{1}\right)$ solutions were used and the resultant $\mathrm{NaOH}$ coating densities were 0.70 and $0.35 \mathrm{mg} \mathrm{cm}{ }^{-2}$ 


\section{suments small}

respectively. VPH treatment of the $\mathrm{NaOH}$ coated titanium plate in ammonia humid atmosphere was conduct to grow the titanate nanotubes. Typically, a Teflon holder was used to horizontally hold the titanium plate with both sides exposed above an ammonia aqueous solution $(28 \% \mathrm{wt})$ in a Teflon lining. The Teflon lining was sealed in a stainless autoclave and kept at $150{ }^{\circ} \mathrm{C}$ for $72 \mathrm{~h}$ in an oven. After completion, the same post treatment as described in the first step was conduct as described in first step. A translucent film was form on the titanium plate after it was dried. For comparison purpose, titanate nanotubes with much smaller widths were prepared by traditional LPH method. The titanium metal plate was hydrothermally treated in $\mathrm{NaOH}$ aqueous solution $\left(10 \mathrm{~mol} \mathrm{~L}^{-1}\right)$ at $150{ }^{\circ} \mathrm{C}$ followed by the same post washing and drying procedures. To study the nanotube growth mechanism, the titanate nanotube growth was retarded with weak alkalinity. To do this, $\mathrm{NaOH}$ coating $(0.018$ $\mathrm{mg} \mathrm{cm}^{-2}$ ) was prepared by withdrawing the precursor-grown substrate from $\mathrm{NaOH} / \mathrm{ethanol}$ solution $\left(0.1 \mathrm{~mol} \mathrm{~L}^{-1}\right)$ and dried.

Characterizations: The morphological properties were examined by JSM-6300 (for surface survey) and JSM-890 (for cross-sectional observation) scanning electron microscopes. The microstructures were investigated by TEM Tecnai 20 (F20) with an accelerating voltage of $200 \mathrm{kV}$ under high vacuum. To prepare the TEM sample grid for axial cross-sectional TEM observation, nanotube specimens were embedded in resin. Samples of nanotubes with thicknesses of $60-70 \mathrm{~nm}$ were cut from sample resin blocks using a Leica Ultracut-T ultramicrotome, and collected on pioloform-coated copper TEM grids. A FEI double tilt TEM sample holder was employed throughout the TEM observation. X-ray diffraction (XRD) data of prepared samples were recorded at room temperature by Bruker X-ray diffractometer using $\mathrm{Cu} \mathrm{K \alpha}$ radiation. Raman spectra were examined at room temperature by a Renishaw 100 system Raman spectrometer using $632.8 \mathrm{~nm}$ He-Ne laser as light source. The scattered light was detected with a Peltier-cooled CCD detector with a spectral resolution of $2 \mathrm{~cm}^{-1}$. 


\section{mind \\ suminates small}

Kinetics of ion exchange: The protonated titanate nanotube samples were prepared by removal of the titanate nanotube powder from the substrate by moderate ultrasonic treatment, followed by repeated acid washing in $\mathrm{HCl}$ solution $\left(0.1 \mathrm{~mol} \mathrm{~L}^{-1}\right)$ for $3 \mathrm{~h}$ and water washing in water until the $\mathrm{pH}$ of water reached $\sim 5$. The resultant nanotube samples were dried at $80^{\circ} \mathrm{C}$ under vacuum. The details of $\mathrm{Na}^{+}$ion exchange experiment is described elsewhere. ${ }^{[15 c]}$ Typically, protonated nanotube samples $(4 \mathrm{mg})$ were dispersed in water $(10 \mathrm{~mL})$ under vigorous stirring. Then $\mathrm{NaOH}\left(1 \mathrm{~mol} \mathrm{~L}^{-1}, 5 \mu \mathrm{L}\right)$ or $\mathrm{LiOH}\left(1 \mathrm{~mol} \mathrm{~L}^{-1}, 5 \mu \mathrm{L}\right)$, or $\mathrm{Ba}(\mathrm{OH})_{2}$ solution $\left(0.05 \mathrm{~mol} \mathrm{~L}^{-1}\right.$, $50 \mu \mathrm{L}$ ) was added into the nanotube suspension. The $\mathrm{pH}$ variation was monitored by a glass electrode coupled to a Maclab 400 interface (AD Instruments) at room temperature.

_[1] a) S. Iijima, Nature 1991, 354, 56-58; b) Y. R. Hacohen, E. Grunbaum, R. Tenne, J. Sloan, J. L. Hutchison, Nature 1998, 395, 336-337; c) S. Amelinckx, D. Bernaerts, X. B. Zhang, G. Van Tendeloo, J. Van Landuyt, Science 1995, 267, 1334-1338; d) O. G. Schmidt, K. Eberl, Nature 2001, 410, 168; e) Y. Gogotsi, J. A. Libera, N. Kalashnikov, M. Yoshimura, Science 2000, 290, 317-320; f) R. Tenne, L. Margulis, M. Genut, G. Hodes, Nature 1992, 360, 444-446; g) N. G. Chopra, R. J. Luyken, K. Cherrey, V. H. Crespi, M. L. Cohen, S. G. Louie, A. Zettl, Science 1995, 269, 966-967.

_[2] a) R. H. Baughman, A. A. Zakhidov, W. A. de Heer, Science 2002, 297, 787-792; b) E. J. M. Hamilton, S. E. Dolan, C. M. Mann, H. O. Colijn, C. A. McDonald, S. G. Shore, Science 1993, 260, 659-661; c) L. Margulis, G. Salitra, R. Tenne, M. Talianker, Nature 1993, 365, 113-114; d) Y. Feldman, E. Wasserman, D. J. Srolovitz, R. Tenne, Science 1995, 267, 222-225; e) M. Remskar, A. Mrzel, A. Jesih, F. Lévy, Adv. Mater. 2002, 14, 680-684; f) M. Nath, C. N. R. Rao, Angew. Chem. Int. Ed. 2002, 41, 34513454; g) M. Nath, C. N. R. Rao, J. Am. Chem. Soc. 2001, 123, 4841-4842; h) H. J. Muhr, F. Krumeich, U. P. Schönholzer, F. Bieri, M. Niederberger, L. J. Gauckler, R. 


\section{ation \\ subiniusus $\mathrm{s}$ Smal}

Nesper, Adv. Mater. 2000, 12, 231-234; i) T. Kasuga, M. Hiramatsu, A. Hoson, T.

Sekino, K. Niihara, Adv. Mater. 1999, 11, 1307-1311; j) G. B. Saupe, C. C. Waraksa, H.-N. Kim, Y. J. Han, D. M. Kaschak, D. M. Skinner, T. E. Mallouk, Chem. Mater. 2000, 12, 1556-1562; k) X. Wang, J. Zhuang, J. Chen, K. Zhou, Y. Li, Angew. Chem. Int. Ed. 2004, 43, 2017-2020; 1) T. Kasuga, M. Hiramatsu, A. Hoson, T. Sekino, K. Niihara, Langmuir 1998, 14, 3160-3163; m) Y. Li, J. Wang, Z. Deng, Y. Wu, X. Sun, D. Yu, P. Yang, J. Am. Chem. Soc. 2001, 123, 9904-9905; n) C. Ye, Y. Bando, G. Shen, D. Golberg, Angew. Chem. Int. Ed. 2006, 45, 4922-4926.

_[3] P. Liu, H. Zhang, H. Liu, Y. Wang, X. Yao, G. Zhu, S. Zhang, H. Zhao, J. Am. Chem. Soc. 2011, 133, 19032-19035.

_[4] a) Q. Chen, W. Zhou, G. Du, L. M. Peng, Adv. Mater. 2002, 14, 1208-1211; b) D. V. Bavykin, J. M. Friedrich, F. C. Walsh, Adv. Mater. 2006, 18, 2807-2824.

_[5] S. Helveg, C. Lopez-Cartes, J. Sehested, P. L. Hansen, B. S. Clausen, J. R. RostrupNielsen, F. Abild-Pedersen, J. K. Norskov, Nature 2004, 427, 426-429.

_[6] a) Z. R. Tian, J. A. Voigt, J. Liu, B. McKenzie, H. Xu, J. Am. Chem. Soc. 2003, 125, 12384-12385; b) H. Tokudome, M. Miyauchi, Angew. Chem. Int. Ed. 2005, 44, 19741977; c) Z. V. Saponjic, N. M. Dimitrijevic, D. M. Tiede, A. J. Goshe, X. Zuo, L. X. Chen, A. S. Barnard, P. Zapol, L. A. Curtiss, T. Rajh, Adv. Mater. 2005, 17, 965-971; d) Y. Mao, S. S. Wong, J. Am. Chem. Soc. 2006, 128, 8217-8226; e) A. Riss, T. Berger, S. Stankic, J. Bernardi, E. Knözinger, O. Diwald, Angew. Chem. Int. Ed. 2008, 47, 1496-1499; f) D. V. Bavykin, F. C. Walsh, in Titanate and Titania Nanotubes: Synthesis, Properties and Applications (Eds.: P. O'Brien, H. Craighead, H. Kroto), The Royal Society of Chemistry, Cambridge, UK 2009; g) D. V. Bavykin, F. C. Walsh, Eur. J. Inorg. Chem. 2009, 2009, 977-997. 


\section{minen \\ subiniacus $s$ Smal}

_[7] P. Liu, Y. Wang, H. Zhang, T. An, H. Yang, Z. Tang, W. Cai, H. Zhao, Small 2012, 8, 3664-3673.

_[8] a) R. Ma, Y. Bando, T. Sasaki, Chem. Phys. Lett. 2003, 380, 577-582; b) R. Ma, K. Fukuda, T. Sasaki, M. Osada, Y. Bando, J. Phys. Chem. B 2005, 109, 6210-6214; c) T. Sasaki, M. Watanabe, Y. Michiue, Y. Komatsu, F. Izumi, S. Takenouchi, Chem. Mater. 1995, 7, 1001-1007.

_[9] a) T. Gao, H. Fjellvảg, P. Norby, Inorg. Chem. 2009, 48, 1423-1432; b) S.-J. Kim, Y.U. Yun, H.-J. Oh, S. H. Hong, C. A. Roberts, K. Routray, I. E. Wachs, J. Phys. Chem. Lett. 2010, 1, 130-135.

_[10] a) J. S. Speck, M. Endo, M. S. Dresselhaus, J. Cryst. Growth 1989, 94, 834-848; b) X. F. Zhang, X. B. Zhang, G. Van Tendeloo, S. Amelinckx, M. Op de Beeck, J. Van Landuyt, J. Cryst. Growth 1993, 130, 368-382; c) M. Liu, J. M. Cowley, Ultramicroscopy 1994, 53, 333-342; d) S. Iijima, J. Cryst. Growth 1980, 50, 675-683; e) H. W. Kroto, K. McKay, Nature 1988, 331, 328-331.

_[11] K. Tibbetts, R. Doe, G. Ceder, Phys. Rev. B 2009, 80, 014102.

_[12] a) D. V. Bavykin, V. N. Parmon, A. A. Lapkin, F. C. Walsh, J. Mater. Chem. 2004, 2004, 3370 - 3377; b) S. Zhang, L. M. Peng, Q. Chen, G. H. Du, G. Dawson, W. Z. Zhou, Phys. Rev. Lett. 2003, 91, 256103.

_[13] a) Á. Kukovecz, M. Hodos, E. Horváth, G. Radnóczi, Z. Kónya, I. Kiricsi, J. Phys. Chem. B 2005, 109, 17781-17783; b) H. Zhang, P. Liu, H. Wang, H. Yu, S. Zhang, H. Zhu, F. Peng, H. Zhao, Langmuir 2009, 26, 1574-1578.

_[14] a) J. P. Issi, L. Langer, J. Heremans, C. H. Olk, Carbon 1995, 33, 941-948; b) Y. Asada, F. Nihey, S. Ohmori, H. Shinohara, T. Saito, Adv. Mater. 2011, 23, 4631-4635; c) G. A. Rance, D. H. Marsh, R. J. Nicholas, A. N. Khlobystov, Chem. Phys. Lett. 2010, 493, 19-23; d) R. Fleurier, J.-S. Lauret, U. Lopez, A. Loiseau, Adv. Funct. 
Mater. 2009, 19, 2219-2223; e) S. Okubo, T. Okazaki, N. Kishi, S.-K. Joung, T.

Nakanishi, S. Okada, S. Iijima, J. Phys. Chem. C 2008, 113, 571-575.

_[15] a) R. Ma, T. Sasaki, Y. Bando, Chem. Commun. 2005, 948-950; b) X. Sun, Y. Li, Chem. Eur. J. 2003, 9, 2229-2238; c) D. V. Bavykin, F. C. Walsh, J. Phys. Chem. C 2007, 111, 14644-14651.

_[16] a) D. V. Bavykin, M. Carravetta, A. N. Kulak, F. C. Walsh, Chem. Mater. 2010, 22, 2458-2465; b) J. Suetake, A. Y. Nosaka, K. Hodouchi, H. Matsubara, Y. Nosaka, J. Phys. Chem. C 2008, 112, 18474-18482.

Received: ((will be filled in by the editorial staff))

Revised: ((will be filled in by the editorial staff)) Published online on ((will be filled in by the editorial staff)) 


\section{Figures captions}

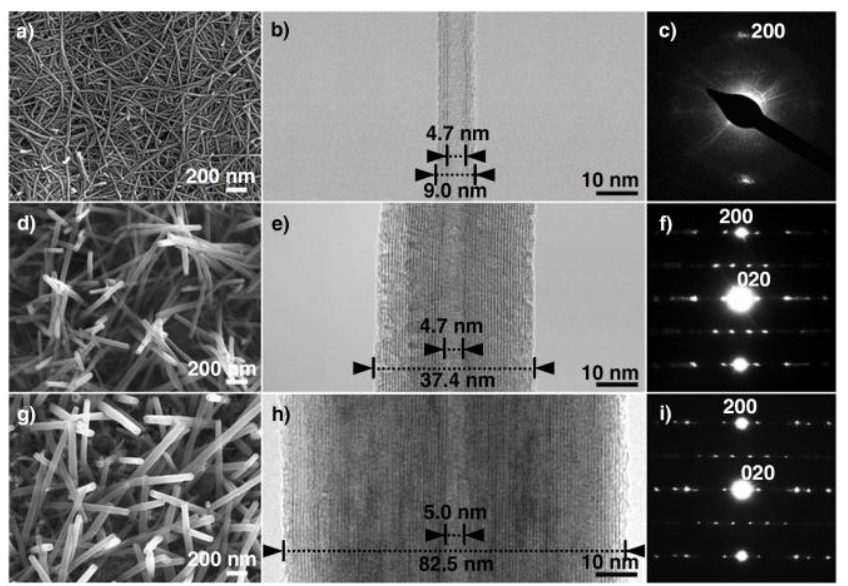

Figure 1. SEM, TEM images and SAED patterns of the nanotube samples prepared by traditional LPH (a-c) and VPH methods (d-f for VPH I sample and g-i for VPH II sample).

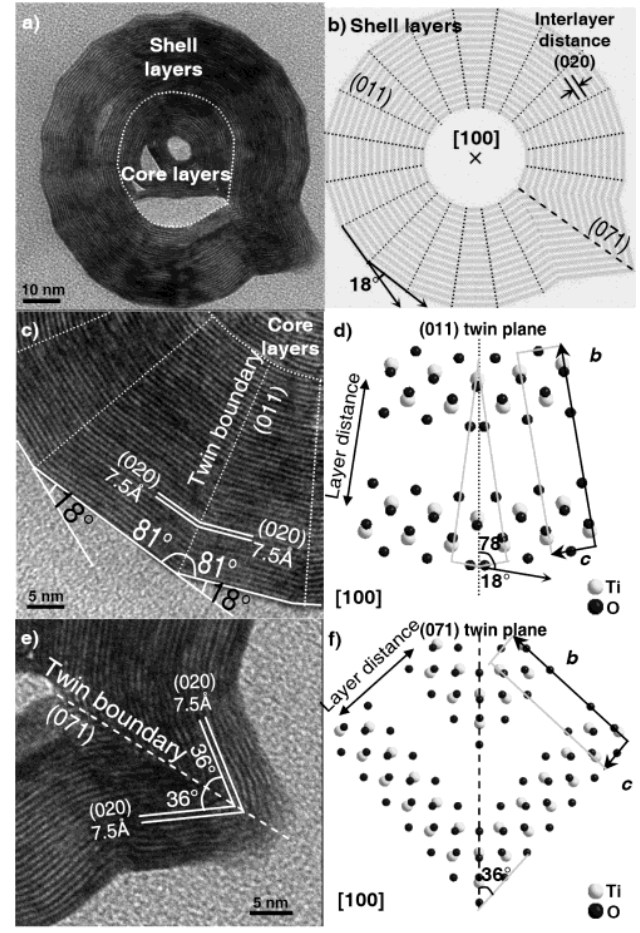

Figure 2. Layered structures of VPH II titanate nanotubes. Axial cross sectional TEM image of (a) a nanotube, (c) nanotube walls and (e) seaming joint. (b) the schematic graphs of shell layer structure of a "perfect" nanotube constructed by identical flat sectors connected by sharing twin planes, (d) the (011) twin boundary between each sectors and (f) the (071) twin boundary of the seaming joint. 
subinied Sto Small

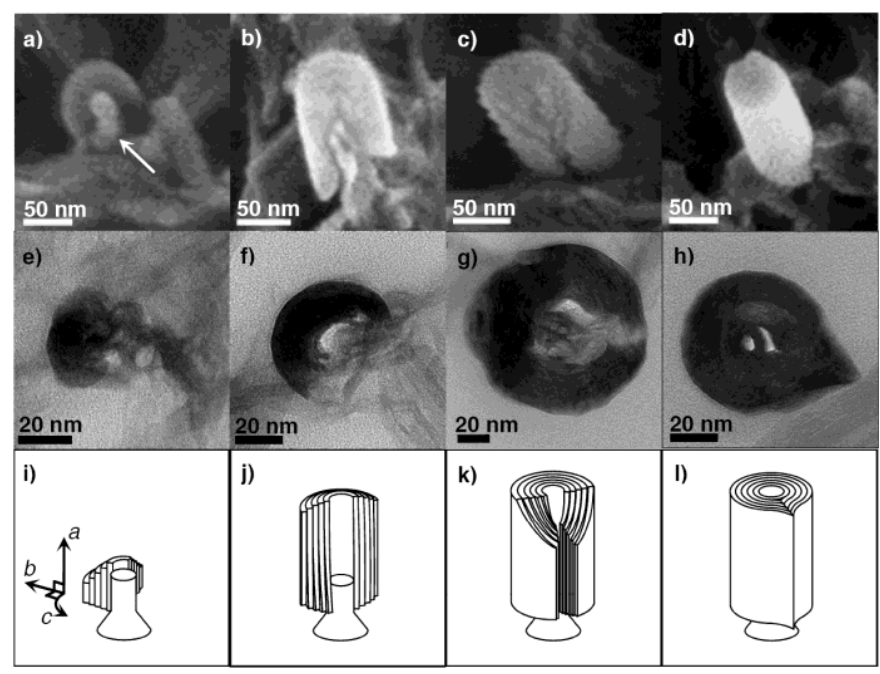

Figure 3. Growth process of the nanotubes prepared in $\mathrm{VPH}$ reaction with thinner $\mathrm{NaOH}$ coating. (a - d) SEM images, (e - h) TEM images and ( $\mathrm{i}-1)$ the corresponding schematic diagrams (not to scale).
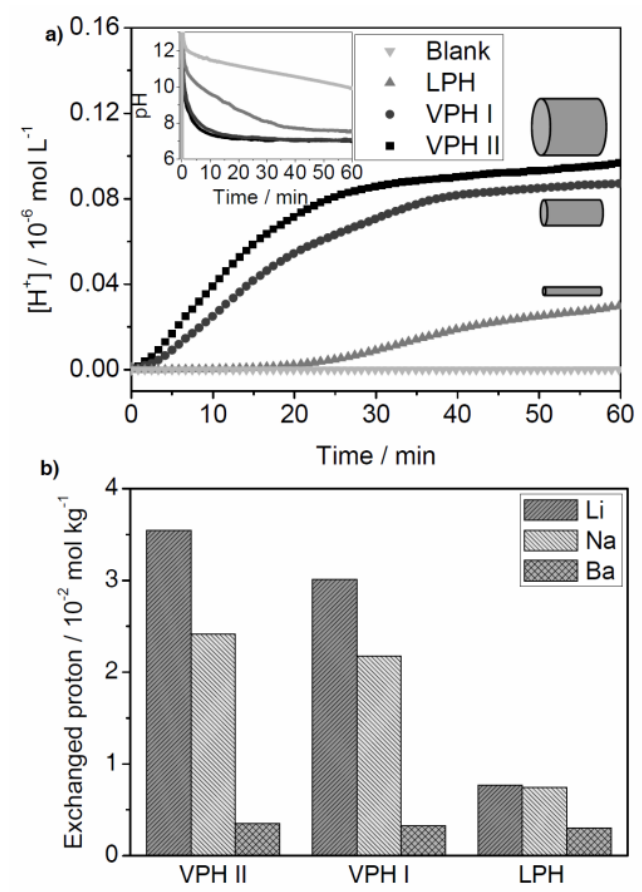

Figure 4. (a) Proton concentration variation during the ion exchange with $\mathrm{Na}^{+}$after addition of $\mathrm{NaOH}$ solution to aqueous suspension of protonated titanate nanotubes. The inset is the corresponding $\mathrm{pH}$ decay profile. (b) Proton exchanged amount after $60 \mathrm{~min}$ ion exchange experiment. 
A new form of nanotubular crystal structure is directly grown by a vapor-phase hydrothermal method via an epitaxial orientated crystal growth mechanism. The as-prepared nanotubes possess a unique multi-tunnel core-shell layered nanotubular structure with droplet shaped polygonal periphery and segmental crystal configuration. They are dimension-tunable and demonstrate superior ion exchange properties in terms of exchange rate and ion accommodating capacity.

Nanotube structure, Vapor-phase, Hydrothermal synthesis, Controllable growth, Growth mechanism

Porun Liu, Haimin Zhang, Hongwei Liu, Yun Wang, Taicheng An, Weiping Cai, Huagui Yang, Xiangdong Yao, Guangshan Zhu, Robyn Webb and Huijun Zhao*

Vapor-Phase Hydrothermal Growth of Novel Segmentally Configured Nanotubular Crystal Structure

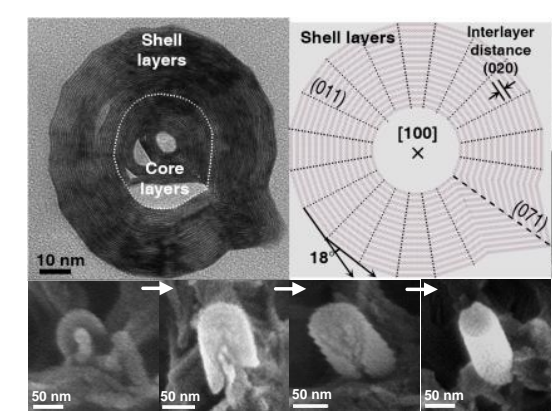

